\title{
Donantes de esperma en los Estados Unidos de América y las relaciones con su descendencia ${ }^{1}$
}

\author{
Rosanna Hertz ${ }^{2}$
}

Recibido: 10 de diciembre de 2017/ Aceptado: 5 de febrero de 2018

Resumen. Nuevas formas de familia están emergiendo en una era de cambios rápidos en las tecnologías reproductivas, particularmente en aquellas tecnologías en las que participan donantes de gametos. El anonimato de los donantes ha resultado ser más problemático conforme más países exigen a los donantes revelar su identidad. En la investigación sociológica aún queda por explorar el rol de los donantes quienes, habiéndose declarado anónimos o no-anónimos en su banco de esperma, han contactado con su descendencia. En los Estados Unidos de América, a los donantes se les pide elegir el tipo de donante que desean ser: anónimo o no-anónimo. Pero poco se sabe acerca de cómo los donantes toman esta decisión, qué piensan acerca de su donación y la descendencia que imaginan haber podido tener, o la posibilidad de cambiar su opinión sobre su anonimato. Teniendo en cuenta la importancia que tiene la identidad para los padres que utilizan donantes de esperma y para los niños, que a menudo desean saber más sobre sus orígenes, esta cuestión merece una mayor atención. A partir de datos provenientes de varias fuentes, se analiza la evolución de las narrativas de los donantes sobre ellos mismos como donantes y sobre su descendencia genética. Los perfiles de donantes en bancos de semen de Estados Unidos en 2003 y en 2017 se utilizan para estudiar posibles cambios en las justificaciones de los donantes para elegir el anonimato o no-anonimato. Las entrevistas en profundidad llevadas a cabo entre 2013-2015 con donantes que han cambiado de opinión ofrecen una oportunidad única para entender sus lógicas y las consecuencias que tiene este cambio para los padres y su descendencia. Esta aproximación hace posible la comprensión del nuevo rol emergente de los donantes en las familias nucleares.

Palabras clave: donante de esperma; industria de la fertilidad, descendientes del donante; donantes no-anónimos; donantes anónimos; familias concebidas por donación.

\section{[en] Sperm Donors in the U.S. and Their Relationships to Offspring}

\begin{abstract}
New forms of family are emerging in an era of rapid change in reproductive technologies, particularly technologies that employ donor gametes. Donor anonymity has become more problematic as more countries require all donors to be identity release. The role of the sperm bank donor -whether anonymous or identity release- who has contact with his offspring remains unexplored in sociological research. In the United States donors are asked to choose the kind of donor they want to be: anonymous or identity release. But little is known about how donors make this decision, including how they think about their donation and their imagined offspring, or whether they change their minds. Given how identity matters to parents who use donor sperm and to children who are often eager to know more about their origins, this topic deserves closer attention. Data from several data sources are used to trace the evolving narrative about donors and their genetic offspring. United States donor profile accounts from 2003 and 2017 are used to explore whether donor justifications about anonymity/identity release have changed. In-depth interviews conducted between 2013-2015 with donors who switch their donor

\footnotetext{
Traducción de Clara Fernández de Bobadilla y Carlos Arca, revisada por Nancy Konvalinka. College, USA.rosannahertz1@gmail.com
}

2 Class of 1919 50th Reunion Professor. Departments of Sociology and Women's and Gender Studies, Wellesley
\end{abstract}


status offer a unique opportunity to understand both their rationales and the consequences of their shift for parents and their offspring. This approach makes it possible to understand the newly emerging role of donors in nuclear families.

Key words: sperm donor; fertility industry; donor offspring; identity release donors; anonymous donors; donor-conceived families.

Sumario. 1. Introducción. 2. Origen de la investigación: expandiendo las categorías de los donantes. 3. Datos. 4. Las motivaciones de los donantes y la decisión de revelar la identidad. 5. El donante desafía las ideas sobre la familia. 6. Cuando los donantes anónimos cambian de opinión. 7. Resumen y conclusión. 8. Referencias bibliográficas.

Cómo citar: Hertz, R. (2018). Donantes de esperma en los Estados Unidos de América y las relaciones con su descendencia, en Revista de Antropología Social 27(1), 307-324.

\section{Introducción}

Los donantes son una parte consolidada de la industria de la fertilidad. Aun así, sabemos bastante poco sobre las motivaciones de los donantes a la hora de revelar su identidad- algunas veces años después de su donación- o de permanecer en el anonimato. Las cuestiones relacionadas con la identidad son importantes para los padres que emplean a un donante de esperma y para los niños que desean saber más con respecto a sus orígenes. Actualmente, cuando los debates en torno a los valores familiares se intensifican y emergen nuevas formas de familia, el rol del donante merece una mayor atención ${ }^{3}$.

En este artículo, emplearé varias fuentes únicas para explorar la evolución de las narrativas sobre ellos mismos como donantes y sobre su descendencia genética. Por ejemplo, compararé perfiles de donantes de 2003 y 2017 para ver si sus justificaciones sobre anonimato/no-anonimato han cambiado. Además, las entrevistas en profundidad con donantes que decidieron modificar su estatus original de anónimo a no-anónimo en el banco, ofrecen una oportunidad única para entender tanto sus lógicas como las consecuencias de este cambio para los padres y su descendencia- particularmente cómo padres e hijos se esfuerzan por explicar algunos comportamientos en base a un origen genético o social. Combinar estos datos nos permite entender mejor cómo donantes y familias construyen conjuntamente un rol para ese extraño, el donante.

Este artículo sugiere que la narrativa sobre el donante ignorante que deposita su esperma y no sabe ni le importa lo que pasará con él, está cada vez más pasada de moda y, posiblemente, nunca se haya ajustado a la realidad. Un nuevo discurso sobre la donación que tiene en cuenta «la futura descendencia» ha surgido. Este discurso está centrado en la reciprocidad: se considera que tanto el donante como el niño concebido por donación tienen derecho a acceder a información sobre el otro. Encontrar un lugar para el donante puede convertirse en el mayor reto para estas familias en los años venideros.

\footnotetext{
3 Los niños concebidos mediante donación que quieren saber más con respecto a sus donantes, habitualmente desean un contacto moderado (Scheib, Ruby y Benward, 2017; Nelson, Hertz y Kramer, 2016).
} 


\section{Origen de la investigación: expandiendo las categorías de los donantes}

En mis anteriores investigaciones en torno a las madres solteras $(2002,2006)$, origen de este artículo, se tuvieron en cuenta solo dos categorías de donantes: donantes conocidos (por ejemplo, amigos o miembros de la red social de una mujer) y donantes anónimos de un banco. Las madres solteras que fueron mis informantes solo escogieron entre estas dos categorías. Mientras que las opciones parecían estar divididas, la mayor parte de las mujeres intentaban, en primera instancia, encontrar un donante conocido. Si no podían encontrarlo, iban a bancos y compraban viales de esperma de un donante anónimo. Una vez tomada la decisión, ya no se podía cambiar - estas mujeres suponían que el donante sería anónimo para siempre-. Ambos tipos de donación -conocida y anónima- ofrecían a las familias monoparentales madre-hijo diferentes maneras de imaginar al donante. Aquellas madres que encontraron donantes conocidos proporcionaron a los niños información personal sobre ellos porque eran o viejos amigos o parte de su círculo social. La implicación del donante con el niño variaba y, a veces, se intensificaba. Por el contrario, aquellas madres que escogieron donantes anónimos para sus hijos se apoyaban en una imagen ficticia del donante co-producida con sus hijos. Mientras estos crecían, algunos de sus rasgos -desde la apariencia física hasta el carácter, el comportamiento y los intereses- eran atribuidos al donante anónimo.

Las mujeres a las que entrevisté viven en la parte este de Massachusetts y todas ellas habían escogido a donantes anónimos o de dos grandes bancos de esperma nacionales con implantación en clínicas locales o de un banco de esperma regional. Cuando empecé mi investigación en 1995, los donantes anónimos ya existían en los Estados Unidos de América. No obstante, las mujeres de mi estudio, representativas de las que conocí cuando asistía a encuentros de la delegación local de la Organización Nacional de las Madres Solteras por Elección, debatían únicamente sobre el uso de un donante conocido frente a un donante anónimo de un banco de esperma. Estas mujeres no manifestaban haber intentado buscar un donante no-anónimo. Esto podría ser debido a que los donantes no-anónimos se encontraban más fácilmente en dos pequeños bancos sin ánimo de lucro de la costa Oeste. Hoy en día, todos los bancos de los Estados Unidos de América ofrecen donantes no-anónimos. Cuando un potencial cliente busca en la página web de un banco de esperma, encuentra toda una compleja gama de opciones de filtrado: el tipo de donantes es un criterio posible que los clientes pueden utilizar.

\section{Los derechos de los niños: un catalizador para el cambio hacia una mayor apertura en la identidad de los donantes de los bancos de esperma}

Como una forma de protegerse legalmente, tanto el donante como los padres intencionales que compran el esperma se comprometen a lo que Maureen Sullivan (2004, p.35) se refiere como «sistema de ignorancia bilateral de la paternidad» ${ }^{4}$. El donante con su firma renuncia a los derechos de paternidad con respecto a los niños concebidos a partir de su donación de esperma. Los padres acuerdan

$4 \quad$ El término utilizado en inglés es «system of bilateral ignorance of paternity». 
que no reclamarán la paternidad del donante. El razonamiento de la industria de la fertilidad para mantener el anonimato y no pedir a todos los donantes que estén de acuerdo con revelar su identidad cuando el niño alcance 18 años, se ha vuelto crecientemente sospechoso. No existe ninguna ley en los Estados Unidos de América, tanto a escala federal como a escala de los distintos estados, que prohíba el anonimato del donante o que exija que los bancos de semen revelen la identidad del donante al cumplir el niño los 18 años ${ }^{5}$. En contraste con esto, hay países, como el Reino Unido, que tienen leyes que prohíben el anonimato de los donantes. La mayoría de estos países exigen que los donantes incluyan información que les identifique en un registro nacional al que tienen acceso los niños al cumplir los 18 años. Su intención es garantizar que los niños tengan información sobre sus orígenes genéticos ${ }^{6}$. Ya que estos cambios en el anonimato de los donantes son recientes y los niños nacidos desde la implementación de estas prohibiciones todavía no han cumplido los 18 años, no sabemos cómo afectarán estos cambios a la formación familiar. En la segunda parte de este artículo, abordaré los posibles resultados en los casos en los que los donantes se presentan y cómo es su inserción en las familias ${ }^{7}$.

Los padres y sus hijos concebidos por donación, de hecho, quieren información actualizada (información médica y actualizaciones sobre las declaraciones personales que los donantes proporcionan a las clínicas) de los perfiles originales que tienen de cuando compraron el esperma. Además, cada vez más niños concebidos por donación, que tienen ahora 18 o más años, argumentan que tienen derecho a la información que se les ha denegado con respecto a sus identidades. La mayor parte de los bancos de esperma de los Estados Unidos está aumentando el número de donantes no-anónimos y buscando formas de incrementarlos (Cohen et al., 2016). Pero existe ya, por lo menos, un banco más pequeño en los EE. UU. que ha decidido dejar de ofrecer donantes anónimos, aceptando únicamente donantes dispuestos a formar parte de su programa de revelación de la identidad. Además, hay registros independientes (al margen de los bancos de esperma) que se han convertido en sitios web donde los donantes de esperma -sea cual sea la categoría que escogieron cuando entraron al programa del banco de donantes- pueden ahora indicar que están dispuestos a establecer contacto. Pese a que no es demasiado probable que

5 De todos los estados americanos, únicamente el estado de Washington tiene una nueva ley que garantiza el acceso de los niños concebidos mediante donación de semen o de óvulos al nombre completo y al historial médico de su donante, a no ser que el o la donante opte por no ser identificado. El anonimato de los y las donantes no está completamente prohibido en el estado de Washington. Esta ley erosiona el anonimato de las y los donantes, pero no llega a una prohibición plena con respecto a esta práctica.

6 Igual que el Reino Unido, Finlandia, Alemania, Irlanda, Suecia, Suiza, los Países Bajos, Noruega, Nueva Zelanda y el estado australiano de Victoria han regulado que los niños puedan tener acceso a la información de los donantes a los 18 años. Sin embargo, otros países como España, Francia y Dinamarca han promulgado leyes que protegen el anonimato de los donantes. Si los padres intencionales que viven en un país desean un tipo de donante que no se permite allí, siempre pueden comprar semen online o viajar a otro país (véase Hertz et al., 2016).

7 Puntualizo el hecho de que, entre los países que ahora prohíben el anonimato, el cambio en la ley solo es para donantes nuevos en adelante. En el Reino Unido, que prohibió el anonimato de los donantes en 2005, los niños nacidos bajo esta nueva ley tendrán la primera oportunidad de preguntar por la identidad de sus donantes en 2023, cuando cumplan los 18 años. No obstante, merece la pena apuntar que el estado de Victoria en Australia ha sido la primera instancia jurisdiccional en proporcionar información sobre donantes que habían donado antes. No sabemos cómo afectarán estos cambios a la formación familiar. Este es un campo que sería muy interesante como objeto de un proyecto de investigación 
una gran proporción de donantes anónimos cambien de opinión, aquellos que lo han hecho nos ofrecen un atisbo de por qué lo hicieron y qué tipo de relaciones han desarrollado con su descendencia ${ }^{8}$. Aun así, no sabemos qué es lo que motiva a los donantes a escoger una denominación específica -anónimo o no-anónimo- en el momento del ingreso.

\section{Datos}

Para la primera sección del análisis, he utilizado cincuenta perfiles de donantes seleccionados de un banco estadounidense en dos momentos diferentes: 2003 y $2017^{9}$. Para explorar las similitudes y diferencias entre las motivaciones de los donantes, se plantearon dos preguntas: ¿por qué decidiste ser un donante? y ¿por qué escogiste este tipo de donación (anónima o no-anónima)?

La segunda sección del artículo se basa en diez entrevistas en profundidad que llevé a cabo entre 2013 y 2015 con hombres que decidieron revelar su identidad ${ }^{10}$. No es fácil encontrar donantes de banco de esperma ni hombres que admitan haber donado esperma. Los datos para esta parte del artículo provienen de dos investigaciones diferentes que incluyen donantes sin tener en cuenta su estatus en la revelación de la identidad. Las entrevistas en profundidad se realizaron en el marco de un estudio comparativo sobre donantes de óvulos y de esperma (2013-2014), financiado por una pequeña subvención del Wellesley College. Estos donantes se manifestaban en foros donde discutían sus experiencias. Incluyen donantes conocidos por los padres intencionales, así como donantes de bancos de esperma: tanto donantes anónimos como no-anónimos. Las entrevistas del estudio del Wellesley College nos permitieron comprender mejor las entrevistas a los donantes del estudio de mayor envergadura sobre las familias concebidas mediante donación, subvencionado por la National Science Foundation (NSF) (2014-2017). Los padres o los hijos concebidos mediante donación nos pusieron en contacto con sus donantes, cuando estos habían revelado su identidad. En ambos estudios cualitativos, hay un pequeño grupo de donantes que cambió su estatus de anónimo a noanónimo de forma inesperada.

En este artículo examino únicamente aquellos donantes que decidieron cambiar su estatus de anónimo a no-anónimo. Estas entrevistas nos proporcionan información sobre por qué los donantes cambiaron de opinión, cómo se presentan a sí mismos a su descendencia genética -a la que también llaman «hijos por

8 Varios países se muestran preocupados con respecto al efecto que tendría sobre el número de donantes la exigencia de revelar su identidad. Mediante un diseño experimental, Cohen et. al. (2016) exploraron qué pasaría si en los Estados Unidos se prohibiera la donación anónima y cuánto dinero se pediría a los donantes para mantener su anonimato. Esta discusión va más allá de lo que trata este artículo.

9 Los perfiles fueron creados en los cinco años anteriores a la fecha en la que los descargué. Los perfiles descargados en 2003 fueron preparados por el personal del banco a partir de los datos del período de enero de 1997 a diciembre de 2002; los de 2017, a partir de los datos del período de octubre de 2012 a abril de 2017. Cada uno de los grupos representa un periodo de tiempo discreto, pese a que por simplicidad estoy empleando las fechas en las que descargué los perfiles.

10 El proyecto de la National Science Foundation (Co-PIs Hertz y Nelson) «Social and Bio-Genetic Factors of New Forms of Family» (Factores sociales y biogenéticos de las nuevas formas de familia) incluye a los donantes como parte de las redes familiares. La mayoría forman parte de un proyecto distinto acerca de las donantes de óvulos y los donantes de esperma. 
donación»- concebida con su esperma y cómo negocian su rol en una institución compleja y cambiante.

El material seleccionado cubre 20 años de mi propia investigación y trata específicamente los casos que presento. Ninguna de estas fuentes de datos eran muestras aleatorias, pero cada una de ellas proporciona información útil sobre la naturaleza fluida de los tipos de donantes y sobre las razones cambiantes que los donantes ofrecen para explicar sus acciones actuales.

\section{Las motivaciones de los donantes y la decisión de revelar la identidad}

En 2003, descargué los primeros 25 perfiles numerados consecutivamente de la página web del Banco de Esperma de California (TSBC) ${ }^{11}$. En aquel momento los donantes podían escoger entre donación anónima y donación no-anónima. Si elegían revelar su identidad, debían estar disponibles para ser contactados por su futura descendencia a partir de los 18 años. En 2017, repetí el procedimiento, descargando los 25 primeros perfiles numerados consecutivamente de los donantes recientes. En 2014, TSBC había dejado de aceptar nuevos donantes que deseasen permanecer en el anonimato. Sus donantes, actualmente, firman un contrato que permite al banco revelar su identidad a los niños concebidos mediante donación cuando alcanzan los 18 años ${ }^{12}$.

Al final de cada perfil de donante, había dos preguntas que constituyen la base de esta investigación. La primera preguntaba: «¿Por qué quieres ser un donante de esperma?». La segunda preguntaba acerca de la revelación de la identidad. En 2003, a los donantes se les preguntaba: «¿Has escogido ser un donante no-anónimo? [Sí o No] ¿Por qué tomaste esta decisión?». En 2017, la formulación de la pregunta había cambiado ligeramente para reflejar la política de TSBC que obligaba a revelar la identidad: «Te has unido al programa de revelación de la identidad. ¿Qué te atrae de este programa?». La redacción de las dos preguntas es lo suficientemente similar como para permitir un análisis de contenido consistente ${ }^{13}$.

Como se muestra en la Tabla 1, en 2003 la mayoría de los donantes (60\%) eran anónimos; el cambio en 2017 es producto de un cambio en la política del TSBC. Aun así, los donantes en 2003 y 2017 provienen, más o menos, de los mismos contextos raciales y étnicos. La mayoría se identifican a sí mismos como blancos (su etnicidad o las zonas de procedencia de sus familias son Europa, Europa Oriental u Oriente Medio; la mayoría son de países europeos). Hay más donantes hispanos en 2017 que en 2003 y menos donantes afroamericanos en 2017.

11 El Banco de Esperma de California es un banco sin ánimo de lucro que desarrolló el primer programa de revelación de la identidad en el mundo (www.thespermbankofca.org/why-choose-tsbc).

12 Los hombres que quieren permanecer en el anonimato son derivados a otros bancos que todavía aceptan esta categoría de donante.

13 En la descarga de 2017, solo 5 de los perfiles de los donantes contenían esta nueva formulación. Habían sido preparados por el staff en abril de 2017. El resto de los perfiles contenían la antigua formulación y habían sido preparados entre octubre de 2012 y abril de 2017. 
Tabla 1: Perfiles de donante

\begin{tabular}{|c|c|c|}
\hline & \multicolumn{2}{|c|}{ Perfiles de donante } \\
\hline & 2003 & 2017 \\
\hline Demografía & $(\mathrm{n}=25)$ & $(n=23)$ \\
\hline Asiático (Este y Sur) & $12 \%$ & $4 \%$ \\
\hline Africano Americano/ Negro Americano & $8 \%$ & $4 \%$ \\
\hline Hispano (América Central y Sudamérica) & $4 \%$ & $22 \%$ \\
\hline Blanco (Europa, Europa del Este, Oriente Medio) & $68 \%$ & $61 \%$ \\
\hline Mixto (Blanco, Asiático) & $8 \%$ & $9 \%$ \\
\hline Tipo de donación & & \\
\hline Revelación de la identidad & $40 \%$ & $100 \%$ \\
\hline Anónima & $60 \%$ & - \\
\hline Razón por la que se dona (ordenada por rango) & Orden de rango & Orden de rango \\
\hline Económica & 1 & 1 \\
\hline Ayudar a otras personas & 2 & 2 \\
\hline Querer transmitir los genes propios & & 3 \\
\hline Conocer a personas que han necesitado un donante & & 4 \\
\hline Razón por la que se elige la revelación de la identidad & $\begin{array}{l}(\mathrm{n}=10, \text { solo una } \\
\text { respuesta) }\end{array}$ & $\begin{array}{l}\text { ( } \mathrm{n}=25, \text { múltiples } \\
\text { respuestas) }\end{array}$ \\
\hline Derechos de los niños/justicia & $90 \%$ & $84 \%$ \\
\hline Curiosidad de los niños & $10 \%$ & $32 \%$ \\
\hline Curiosidad del donante por su descendencia & & $32 \%$ \\
\hline Deseo del donante de formar parte de la vida de los niños & & $20 \%$ \\
\hline Importancia de los genes & & $12 \%$ \\
\hline Otro o sin respuesta & & $16 \%$ \\
\hline Razones para elegir el anonimato & $\begin{array}{l}(\mathrm{n}=15, \text { solo una } \\
\text { respuesta) }\end{array}$ & \\
\hline Preocupación por las consecuencias & $33 \%$ & \\
\hline No ser el padre/protegerse de una demanda de paternidad & $27 \%$ & \\
\hline Indeciso: podría cambiar de opinión en el futuro & $20 \%$ & \\
\hline Sin interés en la descendencia & $13 \%$ & \\
\hline Sin respuesta & $6 \%$ & \\
\hline
\end{tabular}


Las motivaciones para donar esperma se mantienen sin grandes cambios en ambos grupos. Esto es, las dos principales razones fueron económicas y altruistas ${ }^{14}$. Aun así, en 2017, a la pregunta abierta, «¿Qué te atrae de este programa?» [el programa de revelación de la identidad], encontré nuevas razones para donar: transmitir los genes y conocer personalmente a personas que han necesitado un donante. Por sí mismas, estas respuestas adicionales contribuyen muy poco a entender por qué algunos escogen revelar su identidad y otros permanecer en el anonimato. Como veremos cuando revisemos sus respuestas escritas, el deseo novedoso de transmitir los genes revela una fuente de motivación no apreciada hasta entonces: la posibilidad de una mayor conexión personal.

Esta cuestión cobra importancia cuando comparamos las razones por las que se elige la revelación de la identidad o el anonimato. En 2003, los donantes no-anónimos estaban convencidos de que los niños tienen derecho a conocer sus orígenes. Esto no ha cambiado de forma significativa en 2017. Sin embargo, cuando se les ha dado la posibilidad de profundizar en la explicación de su decisión de ser donante no-anónimo, han revelado un deseo que antes no consideraban: querían saber más con respecto a su descendencia. Asimismo, estos donantes también indicaban su voluntad de involucrarse en la vida de estos niños.

La importancia del cambio -incluso teniendo en cuenta las diferencias entre los dos conjuntos de datos- se clarifica cuando exploramos las explicaciones detalladas que nos dan los donantes sobre sus decisiones respecto al anonimato y la revelación.

\section{Donantes anónimos en 2003}

Cuando los hombres se hacen donantes, saben que un niño puede nacer de su donación. Algunos prefieren pensar en donar esperma como si fuera donar sangre: un acto sin consecuencias futuras para ellos. Uno de ellos lo expresó claramente: «En este momento de mi vida, no quiero pensar en lo que podría resultar de mi donación». Aun así, la mayor parte de los donantes sí contemplan las consecuencias, particularmente las consecuencias legales. Por ejemplo, un donante escribió:

[...] No quiero que ninguna maniobra legal posible pero imprevista me obligue a ser un «padre» o un tutor, puesto que, en este momento, no tengo ese deseo. A pesar de que las leyes actuales protejan mi derecho a la privacidad, hay leyes que a la larga pueden ser cambiadas/enmendadas.

Otros se preocupaban sobre las consecuencias que la donación tendría para sus futuras esposas y familias: «En este momento escojo no revelar mi identidad por el temor a que una futura esposa pueda no sentirse cómoda con la idea de que yo sea un donante de esperma y que los niños nacidos de mis genes puedan contactarme». Otro se preocupaba por lo mismo, pero también admitía preocuparse por sus propios

14 Para investigaciones que comparan a los donantes de esperma y de óvulos y cómo entienden su donación, ver Almeling (2014), Nelson y Hertz (2017). Para una discusión sobre cómo las mujeres pertenecientes a diferentes tipos de familia imaginan a los donantes de esperma frente a las donantes de óvulos cuando hacen su selección, sobre cómo imaginan su contribución genética a las características de los niños y sobre cómo seleccionan donantes de óvulos y donantes de esperma en función de rasgos distintos, ver Hertz, Nelson y Kramer (2015) 
sentimientos: «Creo que sería muy incómodo, no solo para mí, sino también para mi futura esposa e hijos, si un desconocido se acercara a mí para establecer contacto».

En los perfiles de 2003, los donantes anónimos parecían más preocupados por su propia necesidad de anonimato que por el deseo de su descendencia de obtener información. Un hombre hacía énfasis en el significado de «padre»: «Puedo compartir una mayor conexión con ese niño que con un completo extraño, pero lo que hace a un 'padre' y a un 'hijo' es el amor, los valores, los años de apoyo y otras cualidades inconmensurables que van mucho más allá del simple material genético». Otro lo decía de este modo: «[...] yo no creo que hablar conmigo le fuera a enseñar a nadie algo más sobre ellos mismos y quiénes son. Los padres, biológicos o no, son de lejos la mayor influencia en la personalidad de alguien».

Aun así, el 20\% de los donantes anónimos se declaraban inseguros sobre su decisión de ser anónimos. Un hombre titubeaba: «Tomé esta decisión porque nunca lo había hecho antes. Empecé como un donante no-anónimo, pero decidí cambiar porque siempre cabría la opción de dar marcha atrás [de donante anónimo] y ser un donante no-anónimo si veía que todo iba bien». Este donante creía maximizar sus opciones futuras si elegía el anonimato al ofrecerse como donante.

\section{Donantes no-anónimos en 2003}

Para aquellos que eligieron revelar su identidad, la donación no finalizaba al donar el semen. La principal razón es que estos donantes consideraban que los niños concebidos a raíz de su donación tenían derecho a conocer su herencia genética. Como un hombre escribió: «Yo escogí 'sí porque, desde mi punto de vista, el niño tiene el derecho a saber quién es su padre o madre biológico/a. Además, esto podría arrojar un poco de luz sobre la vida del niño». En estas respuestas, se aprecia cómo se mezclan los derechos de los niños con la creencia de que los genes forman parte de su identidad. Ser un «padre biológico» conlleva alguna obligación de, al menos, revelarse a la descendencia que pudiera querer conocerle. Es más, algunos de los hombres tomaron esta decisión pensando en cómo se sentirían ellos de ser un niño concebido mediante donación: «Estoy muy interesado en mi propia ascendencia; sería lamentable si ellos no tuvieran ningún medio para conocer la suya».

Estos temas se hacen aún más explícitos en los perfiles de 2017.

\section{Donantes no-anónimos en 2017}

En perfiles más recientes de donantes, los derechos de los niños son la razón principal por la que los donantes eligen ser donantes no-anónimos. Estos donantes matizan su declaración indicando que «algunos niños» podrían querer conocerlos. Enfatizan que mediante la donación ayudan a los padres, pero que también quieren ayudar a los niños a conocer más acerca de su identidad. Por ejemplo, un hombre escribió: «Creo que cualquier niño nacido de mis genes merece saber de dónde proviene. No creo que sea justo para ellos confiar únicamente en un trozo de papel para decirles todo lo que quieren saber; esto les dejaría con demasiadas preguntas sin responder». Del mismo modo, otro hombre explicaba: «Me gustaría pensar que estoy eligiendo la opción de dejar a mi descendencia elegir una opción. ¿Por qué debería alguien tener el derecho de privarles de información sobre ellos mismos?» 
Estos donantes se imaginan su descendencia como curiosa con respecto a sus orígenes. Como este hombre escribió: «Si yo fuera un niño, me gustaría saber sobre mis padres biológicos tan solo por curiosidad. Por eso quiero dar a mi descendencia la misma oportunidad que a mí me hubiera gustado tener». Otro trazó un paralelismo personal:

Es algo humano tener curiosidad con respecto a de dónde venimos. Yo paso mucho tiempo mirando mi árbol genealógico, he paseado por el barrio en el que mis abuelos crecieron (pese a que nunca conocí a ninguno de ellos)... No querría negar a nadie la capacidad de aprender sobre de dónde provienen, si ellos desean hacerlo, como yo he sido capaz de hacer...

Los donantes en 2017 no solo imaginan a su descendencia como curiosa, sino que ellos mismos admiten sentir curiosidad sobre los niños resultado de su donación: «Honestamente, yo sentiría curiosidad con respecto a cómo es mi descendencia. ¿Qué aspecto tienen? ¿Qué cosas les gustan?» Aunque los donantes no concebían a la descendencia por donación como sus hijos, aceptaban cualquier nivel de implicación en la vida de los niños que estos (y sus padres) determinasen. Algunos donantes imaginaban las futuras relaciones como algo más que meramente informativas: «Me imagino sintiéndome feliz de mayor dándoles consejos, guiándolos; como un recurso de apoyo y cuidado para su verdadera familia». Y otro hombre escribe: «Me encantaría llegar a conocerlos y ser tan parte de sus vidas como ellos me permitieran».

El acto de revelar la propia identidad se lleva a cabo no solo por el bien del niño, sino por el hecho de que permitiría al donante tener un «lugar» en la vida del niño. Los donantes resaltan que ellos no son padres pero que este lugar en la vida del niño tiene más bien el carácter de «apoyo». Es decir, más bien como un tío afectuoso cuya presencia en la familia varía. El comentario de este donante condensa lo que otros han escrito al indicar que estamos en un momento en el que ser un donante supone más reciprocidad que en el pasado:

No veo la necesidad de mantener la privacidad más allá de proteger mi identidad y me gustaría ofrecer a alguien la oportunidad de conocer más detalles sobre su ascendencia si así lo quisieran. ¡También me encantaría saber quién y qué ha pasado con la familia a la que he donado! [Énfasis añadido en itálica porque la donación es menos probable que sea un secreto hoy en día que en el pasado.]

Finalmente, el nuevo conocimiento sobre la importancia de los genes es una de las razones que muchos donantes manejan para ser un donante no-anónimo. Prácticamente, a diario, la prensa publica noticias sobre la importancia de los genes para entender el comportamiento e incluso las oportunidades que tenemos en la vida. Esta narrativa popular inclina la balanza en la dirección de la naturaleza en el debate entre la naturaleza y la crianza -llevando a estos hombres a considerar más seriamente la influencia que tienen sus genes en los niños concebidos mediante su donación-.

Dos ejemplos ilustran este punto. En su perfil, uno de los donantes enfatizaba la naturaleza estática del perfil del donante y cómo el acto de convertirse en un donante no-anónimo permitía a su descendencia acceder a una información médica actualizada: 
Las nuevas tecnologías pueden mejorar la forma en que entendemos y predecimos las enfermedades o afecciones heredadas de nuestros familiares. Me gustaría ponerme a disposición de cualquiera de mis descendientes que pudieran querer este tipo de información de mi parte.

Otro donante, que escribió acerca del nuevo énfasis en los genes lo señalaba de este modo:

Incluso si uno quiere y respeta a sus padres y no pudiera ser más feliz con su crianza, es posible que siga habiendo preguntas sin respuesta sobre uno mismo. Cada vez aprendemos más y más sobre el modo profundo como la genética afecta a múltiples aspectos de nuestras vidas, desde la salud al comportamiento. Todo el mundo debería tener cierto acceso a algo de información sobre su propia identidad genética.

En resumen, la comparación de los perfiles de los donantes de ambos periodos de tiempo (2003 y 2017) revela un desplazamiento en la perspectiva de los donantes desde una perspectiva en la que depositan el esperma y desaparecen, a otra en la que contemplan las relaciones futuras como una obligación. Esto sugiere que está emergiendo una nueva reciprocidad entre el donante y la familia que recibe la donación.

Los perfiles tan solo pueden sugerir los roles que los donantes imaginan para ellos mismos. Aun así, las entrevistas en profundidad llevadas a cabo entre 2013 y 2015 ofrecen una mirada única al proceso mediante el cual algunos donantes conforman activamente un rol para sí mismos en las familias receptoras.

\section{El donante desafía las ideas sobre la familia}

Los donantes anónimos a veces cambian de opinión ${ }^{15}$. Su decisión de ser un donante anónimo o no-anónimo no se puede cambiar a través del banco de esperma. Sin embargo, pueden inscribirse en un registro independiente de tal forma que su descendencia genética y los padres de estos niños puedan encontrarlos. Los donantes que deciden revelar su identidad - tanto aquellos que decidieron ser anónimos en el momento de la donación como aquellos que deciden revelar su identidad antes de que el niño cumpla los 18 años- pueden registrarse voluntariamente y esperar a que las familias actúen y estén de acuerdo en contactar con ellos.

¿Qué lleva a algunos donantes a revelar su identidad? Y, una vez conocida, ¿en qué clase de pariente se convierten? Un hombre al que entrevisté lo describía de la siguiente manera: «En términos simples yo compararía la relación que tengo con los niños como la de un tío que vive en una ciudad diferente, que ve a los niños en alguna ocasión, aunque el nivel de interacción y comunicación varía sustancialmente con cada familia». Este donante registró y reveló su identidad cuando toda su descendencia genética tenía todavía menos de 10 años. ¿Qué sucede cuando los donantes dan el salto de ser un perfil sobre el papel a desear convertirse en algún tipo de pariente para su descendencia por donación?

15 Hertz y Nelson (2018) debaten la aparición de los donantes en el contexto de las redes de hermanos por donación y las respuestas de los niños a estos donantes. 


\section{Cuando los donantes anónimos cambian de opinión}

Como la mayoría de los donantes, los hombres a los que entrevisté y que más tarde tomaron la decisión de revelar su identidad, en un primer momento, no se habían parado a pensar en niños potenciales. Sin embargo, en algún momento pasaron de tener algo de curiosidad a tomarlo en seria consideración. Como un donante señaló:

No pensé en las implicaciones hasta que... ellos [el personal del banco] me dijeron que realmente había niños ahí afuera. Empecé a caer en la cuenta de que había gente real ahí afuera y del impacto de ello. Conforme me fui haciendo mayor y madurando y empecé a imaginarme el tener mis propios hijos, el sentido de cuál era mi responsabilidad se convirtió en una pregunta.

Otros relataban cómo las historias de familiares adoptados o amigos que buscaban a sus padres biológicos les habían llevado a pensar si los niños concebidos mediante su donación albergarían los mismos anhelos. Un donante señaló su conmoción acerca de la historia de una niña que encontró a su donante y lo investigó en Facebook sin que él supiera siquiera que ella existía.

La decisión de inscribirse en un registro independiente podría ser simplemente una forma de satisfacer la curiosidad o podría ser un momento catártico en la vida de un donante. De cualquier manera, en la mente de los donantes que entrevisté, esto desencadenó un proceso de descubrimiento y de búsqueda de sentido sin precedente para los donantes, los padres y los niños.

Para entender este proceso, es importante reconocer que la curiosidad de un donante no acaba necesariamente cuando conoce quiénes son sus descendientes. Los vínculos genéticos con un niño evocan ideas sobre una pertenencia común, como vimos en los perfiles de 2017. En cada entrevista en profundidad, los donantes dijeron que ellos se veían claramente en su descendencia genética. El descubrimiento del parecido físico era, a menudo, el preludio de pensar que la descendencia era como familia, pero no exactamente familia. Estos recordatorios inquietantes de que ese niño es su descendencia genética también implicaban observar las cosas que los niños decían o hacían y que suscitaban sus recuerdos.

Un caso: Anthony nos puso un ejemplo significativo, recordando un episodio con uno de sus descendientes. Nos cuenta su experiencia en primera persona exponiendo su respuesta emocional a las acciones del adolescente:

Le dije: «Déjame caminar contigo. Quiero asegurarme de que llegas a tiempo». Él [el niño de mi donación] hace este razonamiento acerca de cómo puede hacerlo solo, qué haría si perdiera el autobús. Y yo digo, «Dios, ¿a qué me suena eso? Oh no, no». Simplemente la forma como describía las cosas era como un 'facepalm"16. Es cuando te golpeas la frente y dices. «iOh! No me puedo creer que esto haya sucedido». «De acuerdo, es una lógica interesante pero no es realmente correcta».

16 N. de T. facepalm, intraducible. Se refiere a un gesto de exasperación, vergüenza, frustración o disgusto: ponerse la mano en la cara, situando la palma contra ella. Del inglés face: cara, y palm: palma. El gesto se ha hecho popular y se ha incluido en el argot en los últimos años, sobre todo en el uso de los memes. 
Pero esa es exactamente la forma en la que yo lo habría argumentado: que yo no necesito a mi padre donante acompañándome al autobús a esa edad.

Pese a que Anthony compartió estos pensamientos conmigo, no le pareció que debiera comentar con el niño concebido gracias a su donación el parecido entre el comportamiento de este y su propio comportamiento a su edad.

Thomas, otro donante, mencionó que, para él, el rol sorprendente de los genes le hizo encariñarse con el niño resultado de su donación. Lo dijo de este modo: «Fue tan poderoso ver estas cosas con alguien con quien no habías crecido en absoluto. No había tenido ningún contacto, y estas pequeñas similitudes... se sienten tremendamente vinculantes». El parecido físico atrapó a muchos donantes, quienes sintieron una mayor conexión rayana a un sentimiento de responsabilidad.

En algunos casos, la conexión se construyó en torno a la conclusión del donante de que los niños concebidos gracias a su donación podían llegar a sentir que les faltaba una parte de sus vidas. Thomas explicó:

Ella hacía postales del día del Padre para mí cada año y se las quedaba. Ella dijo: «Aquí tienes, Thomas, mira esto». Esa fue la parte que realmente me conmovió y me sentí mal por... hay un sentido de responsabilidad y aquí hay alguien que estaba deseando conocerme. A mí, a su padre biológico. Y yo no estaba ahí.

Anthony, anteriormente citado, sentía que le debía información a su descendencia genética. Creó una página web con fotografías de su familia con la intención de proporcionar a los niños (y a sus padres) una muestra visual de su ascendencia genética. Él ofreció voluntariamente esta información, además, para asegurar a las familias que era una buena persona:

La idea es que un niño interactuando con un adulto tendrá más reparo en preguntar cosas del que tendría un adulto preguntando a un niño. De tal forma que decidí presentar algo de información visual para que estuviera disponible para padres y niños. Ellos pueden tomar la decisión de si quieren contactarme o no y hacerme preguntas, tal vez en base a algunas de estas fotografías.

En conclusión, si bien los donantes pueden decidir satisfacer su propia curiosidad y presentarse como una fuente de información útil, descubren también su impronta genética en estos niños. Poco a poco, pero de forma al parecer inevitable, esto les da una sensación de que, de alguna manera, son responsables del niño. Los sentimientos de responsabilidad, a su vez, despiertan pensamientos sobre una relación duradera.

\section{Estableciendo un nuevo tipo de parentesco}

Los donantes no tienen una guía clara de cuál es o debería ser su rol en la familia. Ser un pariente genético no está vinculado a ninguna obligación social obvia. El acuerdo de donar esperma a un banco exime al donante de cualquier obligación 
legal o económica en los Estados Unidos de América. Así, los donantes tienen que navegar por aguas desconocidas si buscan establecer una relación con su descendencia y con los padres.

En el escenario habitual, los niños deciden a los 18 años si quieren contactar con los donantes. Si desean hacerlo, contactan con el banco de esperma. El personal del banco actúa como un intermediario entre el donante y el niño. Cuando los donantes anónimos deciden que quieren dejar de serlo, el banco no ofrece ningún mecanismo para ello. Estos donantes se pueden inscribir en un registro independiente y si hay familias que figuran con su número de donante, los donantes pueden indicar su voluntad de contactar con su descendencia por donación. Estos donantes que cambian de categoría revierten el proceso de la toma de decisión. Al inscribirse, indican que han cambiado de opinión a las familias que también se han apuntado en el registro independiente. Lo más importante, si los niños son menores legales (todavía no tienen 18 años), es que los padres son los primeros en enterarse de que estos hombres quieren contactar con sus hijos. Los donantes que aparecen a continuación contactaron con su descendencia cuando los niños todavía eran menores de edad. Por mucho que los padres estuvieran interesados en alguna forma de contacto, también estaban vigilantes, en parte porque los niños eran menores y en parte porque las acciones del donante resultaban inesperadas.

Los donantes son conscientes de que su presencia es precaria. Pueden ser expulsados de la vida del niño en cualquier momento. Por ejemplo, Anthony es feliz con cualquier tipo de relación con su joven progenie adolescente. Así que no dice nada. En sus propias palabras, tiene que «mantenerse en un segundo plano»y aceptar las decisiones de los padres sobre cómo educan a sus hijos: «Hay ocasiones en las que se me pasa por la cabeza que yo no lo haría así, pero no puedo decirlo». Considera que podrá mantener la relación con el muchacho mientras que no interfiera.

A menudo los donantes descubren que su donación dio lugar a varios niños criados en diferentes hogares-algunos de los cuales ignoran estar vinculados genéticamenteEsto lleva a los donantes a forjar toda una variedad de relaciones. Anthony, por ejemplo, ha conectado con cuatro familias. Como todos los niños son menores, Anthony no tiene un contacto independiente con ellos. Es más, los padres determinan el tipo de contacto que puede tener con los niños, siempre bajo supervisión paterna. En dos de las familias, los padres todavía no tienen interés en conocerlo en persona. Los niños saben de él y han visto su foto, sin embargo, no mantienen contacto directo con su donante. Los padres han compartido las fotos de sus hijos con él y, de vez en cuando, cuando pregunta por ellos, le ponen al día con noticias acerca de la vida de los niños. Con las otras dos familias, Anthony ha establecido vínculos más fuertes. En uno de los casos, asistirá al baile padre-hija con dos hijas genéticas que tiene y que viven en otro estado. Los padres le pidieron que asistiera al evento y parecían bastante entusiasmados con esta aparición pública junto a sus hijas. Otras dos familias viven más cerca de él y las ve ocasionalmente. Mientras que las chicas del baile padre-hija lo llaman «padre», los padres e hijos de las otras tres familias se refieren a él como «donante».

Algunos donantes se han dado cuenta de que cumplen una importante función social en una cultura en la que tener una mamá y un papá sigue siendo la norma. Esto es cierto, a pesar de que cada vez hay más madres solteras y parejas lesbianas que tienen hijos y que han dejado de ser familias marginales (Mamo, 2015). Aun así, el donante no es un miembro convencional dentro de la familia del modo en que lo es un padre o lo podría ser un padrastro. Por el contrario, el donante «pertenece» al hijo 
de la pareja o de la madre soltera, debido a un vínculo genético. De todas formas, cuando otros niños hablan de sus padres, estos niños pueden hablar de su donante. De este modo, los niños presentan al donante tanto como un símbolo de que ellos también tienen un «padre», como de que es un «padre» que no vive con ellos. Este rara vez tiene autoridad dentro de las familias y, la mayor parte del tiempo, permanece en zonas ambiguas alrededor de la familia nuclear.

Curiosamente, pese a haber creado un nuevo tipo de relación, padres y donantes son cautelosos y, normalmente, intentan no dar su opinión el uno del otro. Los padres desean relaciones cordiales con el donante de tal forma que el niño pueda conocerlo. De este modo, el donante siempre tiene un lugar, pero no un sitio en la mesa como parte de la familia. Los padres actúan como guardianes que protegen el derecho de los niños a conocer a su donante; ni desean que este se entrometa en sus vidas como una figura de autoridad ni tampoco que desaparezca completamente. El donante no tiene más remedio que aceptar los términos que ponen los padres ${ }^{17}$.

Los donantes también establecen límites. No todos los donantes son como Anthony, quien está dispuesto a aceptar cualquier rol que le asigne la familia. Otros donantes solo quieren proporcionar información. No se ven a sí mismos con ninguna otra obligación adicional con los niños resultado de su donación. Estos hombres hacen saber desde el principio que quieren una relación limitada. No quieren estar emocionalmente comprometidos con las vidas de estos niños. Se sienten obligados a responder preguntas, pero no a verse involucrados en modo alguno. Mientras que Anthony se siente orgulloso de su descendencia y está emocionalmente comprometido, realizando frecuentes comprobaciones en Facebook para ver las publicaciones de sus padres sobre lo que están haciendo los niños, otro donante, Sam, no tiene interés por conocer en profundidad a su descendencia por donación y no quiere establecer vínculos emocionales con ellos. Él limita sus interacciones simplemente a responder preguntas. Afirma haberse dado a conocer cuando finalmente admitió que de su donación podrían haber sido concebidos niños y que su descendencia genética podría querer conocer más sobre sus genes ${ }^{18}$. Su obligación con una descendencia imaginaria aumentó. Conforme más pensaba en la posibilidad de tener una descendencia genética, también ideaba un plan para distanciarse de ellos. Es decir, inmediatamente después de revelar su identidad, comunicó a su descendencia genética que tiene hijos propios. Estableció que los parientes genéticos no son sus «verdaderos» hijos y que él solo es un padre para sus «verdaderos» hijos a quienes está criando ${ }^{19}$.

Sam no quiere mezclar su rol como donante con el de un padre social que está comprometido emocionalmente con sus hijos. Aun así, al revelar su identidad a su descendencia por donación, el donante reconoce que es un «padre» genético. Aunque mantiene una relación limitada con su descendencia genética, pasa a ser una persona que ha dejado de ser el donante plano, sin vida, del perfil en el papel. Un padre genético que ha revelado su identidad es un nuevo tipo de pariente. Es un pariente genético del niño, pero no un padre adicional, la relación habitual para los miembros de la familia nuclear.

17 Por supuesto hay ejemplos en los medios de comunicación de deadbeat donors que son extraños, excéntricos, que viven fuera de la norma y no son el tipo de persona que su descendencia esperaba conocer. Véase el documental británico, Donor Unknown (2010) dirigido por Jerry Morrow.

18 A los donantes no se les dice cuántos niños han sido concebidos de sus donaciones. Anthony descubre que tiene descendencia cuando ve sus nombres en el registro independiente. Todavía se pregunta sobre cuántos más hay.

19 Ver Hertz y Nelson, capítulo 7 (2018), sobre cómo se siente la descendencia respecto a la decisión de Sam y lo que podrían haber querido de él. 
Además, el proceso de negociación del rol no se limita a la descendencia y a sus padres. También vincula a la pareja del donante y a sus hijos. La descendencia genética del donante puede amenazar los vínculos maritales incluso si donaron su esperma antes del matrimonio. Las esposas actuales también quieren poner límites con respecto a los niños concebidos con la donación de sus maridos. Por ejemplo, un donante explicaba: «Caren [descendencia del donante] quería llamarme papá, y a mí eso me parecía fantástico, pero mi esposa, Anna, no quería que fuera así. No quería que yo me viera con ella. No quería que nuestros hijos la conocieran en absoluto... ella quería otro hijo que fuera nuestro y de repente aparece la niña de mi donación...». Mientras que su esposa quería que su marido limitara su vinculación, este se sentía dividido entre la niña de su donación y su esposa y sus hijos. Los descendientes del donante no son hijos de un matrimonio anterior (por ejemplo, un hijastro). A la vez que el rol de «madrastra» se ha institucionalizado conforme más padres y madres se divorcian y se vuelven a casar, el rol de la esposa del donante y su relación con la descendencia por donación de su marido parece poco clara; Anna no tenía interés en este territorio inexplorado ${ }^{20}$. En otras ocasiones, las esposas pueden acoger la descendencia genética de sus maridos o al menos permanecer neutrales frente a ella. Los donantes informan que deben estar atentos a que su relación con los niños concebidos por su donación no interfiera con los deseos de sus esposas o con la crianza de sus propios hijos.

\section{Resumen y conclusión}

Si bien el anonimato de los donantes puede llegar a ser una cuestión discutible ${ }^{21}$ debido a los avances de las pruebas genéticas, los donantes aún son extraños en la unidad familiar ${ }^{22}$. Como hemos visto, incluso sin esta nueva (y futura) tecnología para revelar la identidad del donante, los donantes de los perfiles de 2017 indican que es más posible que los donantes que son no-anónimos tengan cierta curiosidad con respecto a su descendencia genética. A alguno de estos donantes también les gustaría una relación más recíproca si su descendencia genética quisiera entrar en contacto con ellos. Es decir, no solo quieren proveer información sobre ellos mismos para resolver las preguntas de los niños acerca de su identidad genética, sino que algunos

20 Hay bibliografía respecto al divorcio y los nuevos matrimonios que atiende a las formas en las que las nuevas esposas educan a los niños de diferentes categorías (hijastros, hijos y medio-hijos). La tensión es más fuerte en la esposa que es quien hace la mayor parte de los trabajos de cuidados. Mientras que la custodia legal obliga al marido (y por extensión a su nueva esposa) en estos casos, a determinados días con el niño, el donante y su esposa no tienen ningún requerimiento legal que le dé la custodia del niño si lo conoce antes de los 18 años. En este momento, el rol de la esposa del donante con los hijos genéticos es totalmente voluntaria y no hay establecida ninguna obligación social al respecto. Es más, es muy probable que los descendentes por donación se deban a una acción previa al matrimonio. También hay que tener en cuenta que es posible que la esposa también haya sido donante de óvulos de forma previa a su matrimonio y que, por tanto, podrían aparecer también descendientes genéticos de esta donación. Una comparación entre maridos y esposas que han tenido contacto con los niños por donación del marido y parejas divorciadas y en segundas nupcias podría ser esclarecedora.

21 En el momento actual, Harper, Kennet y Reisel (2016) han alentado a los bancos de esperma a no garantizar el anonimato puesto que el donante ya no está protegido. Las pruebas genéticas de los donantes pueden ser rastreadas si su ADN, o el ADN de un familiar, se añade a una base de datos.

22 Los donantes conocidos pueden ser incorporados a la familia a medida que sus relaciones con los niños aumentan tras el nacimiento del niño, aunque haya acuerdos legales. Ver Ertman (2015), quien mezcla su historia personal con una serie de casos legales. 
de estos donantes también quieren tener un rol en la vida del niño imaginado. Estos donantes reconocen que no son padres: los padres son las personas que educan al niño. Sin embargo, sí reclaman el tener algún tipo de relación con su descendencia genética que no reemplace a los «verdaderos» padres del niño. También hemos visto que algunos donantes están dando un paso tanto al cambiar de opinión como al cambiar de categoría, además de no esperar hasta que el niño cumpla los 18 años. En estos casos, son aún los padres de los niños los que consienten al donante tener un contacto temprano o cualquier tipo de contacto. Cuando los padres están de acuerdo en establecer contacto y presentan los donantes a sus hijos, las diferentes partes -donantes, padres y niños- deben determinar el lugar del donante en el sistema familiar. Este no es un trabajo fácil puesto que no hay precedentes de donantes en la familia nuclear. Del mismo modo que los hombres que siempre fueron donantes conocidos (como amigos o personas de la red social de la madre), los donantes de bancos que dan el paso al no-anonimato pueden fortalecer con el tiempo el vínculo con su descendencia por donación. Estos resultados son generadores de hipótesis que requieren nuevas investigaciones para entender cómo los donantes que revelan su identidad encajan en los paradigmas familiares existentes o crean otros nuevos.

En el futuro, guardar los límites de la familia podría ser menos dramático conforme más donantes salen a la luz y el parentesco se expande para incluirlos voluntariamente. En estos ejemplos exploratorios, los padres y los niños han dado la bienvenida al donante-como una nueva categoría de pariente-aunque con restricciones.

\section{Referencias bibliográficas}

Almeling, Rene (2014). Sex Cells: The Medical Markets for Eggs and Sperm. Berkeley: University of California Press.

Cohen, I Glenn; Coan, Travis; Ottey, Michelle; et al. (2006). «Sperm donor anonymity and compensation: an experiment with American sperm donors». Journal of Law and Biosciences, 1-21. doi:10.1093/jlb/lsw052

Ertman, Martha M. (2015). Love's Promises: How Formal and Informal Contracts Shape all Kinds of Families. Massachusetts: Beacon Press.

Harper, Joyce C.; Kennett Debbie; Reisel, Dan (2016). «The End of Donor Anonymity: How Genetic Testing is Likely to Drive Anonymous Gamete Donation out of Business». Human Reproduction, 31 (1): 1135-40. doi. org/10.1093/humrep/dew065

Hertz, Rosanna (2002). «The Father as an Idea: A Challenge to Kinship Boundaries by Single Mothers». Symbolic Interaction, 25 (1): 1-31.

- (2006). Single By Chance, Mothers By Choice: How Women are Choosing Parenthood without Marriage and Creating the New American Family. New York: Oxford University Press. (Paperback edition, 2008)

Hertz, Rosanna; Nelson, Margaret K. (2018). Random Families: Genetic Strangers, Sperm Donor Siblings and the Creation of New Kin. New York: Oxford University Press.

Hertz, Rosanna; Nelson, Margaret K.; Kramer, Wendy (2015). «Gendering Gametes: The Unequal Contributions of Sperm and Egg Donors». Social Science and Medicine, 147: 10-19.

Nelson, Margaret K.; Hertz, Rosanna; Kramer, Wendy (2015). «Gamete Donor Anonymity and Limits on Numbers of Offspring: The Views of Three Stakeholders». Journal of Law and the Biosciences, 1-29. 
Nelson, Margaret K., Hertz, Rosanna (2017). «Differences between Sperm and Egg Donors with Respect to Responsibility for Their Donor-Conceived Children». New Genetics and Society, 36: 137-158. doi: 10.1080/14636778.2017.1320941

Mamo, Laura; Alston-Stepnitz, Eli (2015). «Queer Intimacies and Structural Inequalities: New Directions in Stratified Reproduction». Journal of Family Issues, 36 (4): 519-540.

Marrow, Jerry (2010). Donor Unknown: Adventures in the Sperm Trade (documentary) Produced by Al Morrow and Hilary Durman, U.K. release.

Nordqvist, Petra (2017). «Genetic thinking and everyday living: On family practices and family imaginaries». The Sociological Review, 1-17. doi: 10.1177/0038026117711645

Scheib, Joanna E., Ruby, Alice; Benward, Jean (2017). «Who requests their sperm donor's identity? The first ten years of Information releases to adults with open-identity donors». Fertility \& Sterility, January: 1-12. doi: 10.1016/j.fertnstert.2016.10.023 